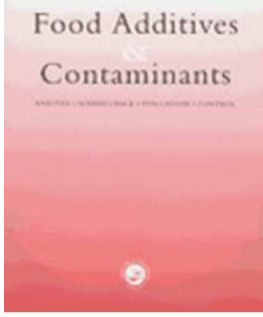

\title{
Dietary Intake of Artificial Sweeteners by the Belgian Population
}

\begin{tabular}{|c|c|}
\hline Journal: & Food Additives and Contaminants \\
\hline Manuscript ID: & TFAC-2011-249.R1 \\
\hline Manuscript Type: & Original Research Paper \\
\hline Date Submitted by the Author: & 18-Sep-2011 \\
\hline Complete List of Authors: & $\begin{array}{l}\text { Huvaere, Kevin; Scientific Institute of Public Health, Food, Medicines and } \\
\text { Consumer Safety } \\
\text { Vandevijvere, Stefanie; Scientific Institute of Public Health, Epidemiology } \\
\text { Hasni, Moez; Scientific Institute of Public Health, Food, Medicines and } \\
\text { Consumer Safety } \\
\text { Vinkx, Christine; Federal Service of Public Health, Food Chain and the } \\
\text { Environment } \\
\text { Van Loco, Joris; Scientific Institute of Public Health, Food, Medicines and } \\
\text { Consumer Safety }\end{array}$ \\
\hline Methods/Techniques: & Exposure assessment, LC/MS, Total diet studies \\
\hline Additives/Contaminants: & Sweeteners \\
\hline Food Types: & Beer, Beverages, Confectionary \\
\hline Abstract: & $\begin{array}{l}\text { In this study it was investigated whether the Belgian population older than } \\
15 \text { years was at risk of exceeding ADI levels of acesulfame-K, saccharin, } \\
\text { cyclamate, aspartame, and sucralose through assessment of usual dietary } \\
\text { intake of artificial sweeteners and specific consumption of table-top } \\
\text { sweeteners. The conservative Tier } 2 \text { approach, for which an extensive label } \\
\text { survey was performed, showed that mean usual intake was significantly } \\
\text { lower than the respective ADIs for all sweeteners. Even consumers with } \\
\text { high intakes were not exposed to excessive levels, as relative intakes at } \\
\text { the } 95 \text { th percentile (p95) were } 31 \% \text { for acesulfame-K, } 13 \% \text { for aspartame, } \\
30 \% \text { for cyclamate, } 17 \% \text { for saccharin, and } 16 \% \text { for sucralose of the } \\
\text { respective ADIs. Assessment of intake using the Tier } 3 \text { approach was } \\
\text { preceded by optimization and validation of an analytical method based on } \\
\text { liquid chromatography with mass spectrometric detection. Concentrations } \\
\text { of sweeteners in various food matrices and table-top sweeteners were thus } \\
\text { determined and mean positive concentration values were included in the } \\
\text { Tier } 3 \text { approach, leading to relative intakes for p } 95 \text { of } 17 \% \text { for acesulfame- } \\
\text { K, } 5 \% \text { for aspartame, } 25 \% \text { for cyclamate, } 11 \% \text { for saccharin, and } 7 \% \text { for }\end{array}$ \\
\hline
\end{tabular}


sucralose of the corresponding ADIs. The contribution of table-top sweeteners to the total usual intake $(<1 \%$ of $A D I)$ was demonstrated to be negligible. Comparison of observed intake of the total population with intake of diabetics (acesulfame-K: 3.55 vs. 3.75 , aspartame: 6.77 vs.

6.53 , cyclamate: 1.97 vs. 2.06 , saccharine: 1.14 vs. 0.97 , and sucralose: 3.08 vs. 3.03 , expressed as mg kg-1 bodyweight day-1 for p95) showed that the latter group was not exposed to higher levels. It was thus concluded that the Belgian population was not at risk of exceeding the established ADIs for sweeteners.

\section{SCHOLARONE ${ }^{\text {M }}$}

Manuscripts 


\section{Dietary Intake of artificial sweeteners by the Belgian population}

2

3 Kevin Huvaere, ${ }^{1}$ Stefanie Vandevijvere, ${ }^{2}$ Moez Hasni, ${ }^{1}$ Christine Vinkx ${ }^{3}$ and Joris Van Loco ${ }^{1^{*}}$

4

$5{ }^{1}$ Department of Food, Medicines and Consumer Safety, Scientific Institute of Public Health,

6 Rue J. Wytsmanstraat 14, B-1050 Brussels, Belgium

$7 \quad{ }^{2}$ Department of Public Health and Surveillance, Scientific Institute of Public Health, Rue J.

8 Wytsmanstraat 14, B-1050 Brussels, Belgium

$9 \quad{ }^{3}$ Belgian Federal Service of Public Health, Food Safety and Environment, Place Victor Horta

1040 box $10, B-1060$ Brussels, Belgium

11

12 Tel: +3226425353

13 Email: Joris.VanLoco@wiv-isp.be 


\section{ABStract}

16

This study investigated whether the Belgian population older than 15 years was at risk of exceeding ADI levels for acesulfame-K, saccharin, cyclamate, aspartame, and sucralose through assessment of usual dietary intake of artificial sweeteners and specific consumption of table-top sweeteners. The conservative Tier 2 approach, for which an extensive label survey was performed, showed that mean usual intake was significantly lower than the respective ADls for all sweeteners. Even consumers with high intakes were not exposed to excessive levels, as relative intakes at the $95^{\text {th }}$ percentile $(p 95)$ were $31 \%$ for acesulfame- $K$, $13 \%$ for aspartame, $30 \%$ for cyclamate, $17 \%$ for saccharin, and $16 \%$ for sucralose of the respective ADIs. Assessment of intake using the Tier 3 approach was preceded by optimization and validation of an analytical method based on liquid chromatography with mass spectrometric detection. Concentrations of sweeteners in various food matrices and table-top sweeteners were thus determined and mean positive concentration values were included in the Tier 3 approach, leading to relative intakes for p95 of $17 \%$ for acesulfame-K, $5 \%$ for aspartame, $25 \%$ for cyclamate, $11 \%$ for saccharin, and $7 \%$ for sucralose of the corresponding ADIs. The contribution of table-top sweeteners to the total usual intake $(<1 \%$ of $\mathrm{ADI}$ ) was demonstrated to be negligible. Comparison of observed intake of the total population with intake of diabetics (acesulfame-K: 3.55 vs. 3.75 , aspartame: 6.77 vs. 6.53 , cyclamate: 1.97 vs. 2.06 , saccharine: 1.14 vs. 0.97 , and sucralose: 3.08 vs. 3.03 , expressed as $\mathrm{mg} \mathrm{kg}^{-1}$ bodyweight day ${ }^{-1}$ for p95) showed that the latter group was not exposed to higher levels. It was thus concluded that the Belgian population was not at risk of exceeding the established ADIs for sweeteners. 


\section{INTRODUCTION}

The desire for sweet taste, commonly referred to as the sweet tooth, is suggested to be an evolutionary legacy of early humans, who survived by their continuous quest for sugary and therefore energy-dense foods (Shils et al. 2005). However, current understanding of medicine has led to the association between lifetime consumption of sugar and a series of adverse health effects, ranging from tooth decay to the increased risk of developing lifethreatening conditions such as obesity and diabetes (Bray et al. 2004; Gross et al. 2004; Ludwig et al. 2001; Touger-Decker et al. 2003). Replacing sugar by intense, artificial sweeteners (also referred to as nonnutritive sweeteners), which possess such sweetening power that relatively small quantities are sufficient to invoke a sweetness equivalent to sugar, is a suggested remedy to reduce sugar intake (Mattes et al. 2009). However, use of such additives in food products is submitted to strict European legislation and maximum permitted levels of sweeteners used in particular foods are stipulated in Directive 94/35/EC (European Parliament and Council 1994). Compounds which are nowadays abundant in sugar-free and sugar-reduced foods as well as in table-top sweeteners include acesulfame-K (E950), aspartame (E951), cyclamate (E952), saccharin (E954), and sucralose (E955). As permissions for applying sweeteners such as neohesperidin dihydrochalcone (E959), neotame (E961), and thaumatin (E957) are more recent, their use is assumed to be less prevalent, while use of steviol glycosides is currently not approved. Beside stating permitted compounds and corresponding maximum levels, the Directive also specifies appropriate food labeling and settles warnings to be listed on foods containing sweeteners. Furthermore, Regulation 1333/2008 of the European Parliament and Council, which includes general guidelines for use of food additives, demands for monitoring use and consumption in different Member States in view of potential legal action if intake levels frequently exceed the advised acceptable daily intake (ADI) (European Parliament and Council 2008).

According to the requirements for data collection, as stipulated in article 22 of Regulation 1333/2008 (European Parliament and Council 2008), the Belgian Federal Service of Public 
65

66

67

68

69

70

71

72

73

74

75

77

78

79

80

81

82

83

84

85

86

87

88

89

90

91

92

Health, Food Safety and Environment conceived a research project to investigate the prevalence of sweeteners on the Belgian market and to evaluate the consumption of these products by the Belgian population. A second objective was to compare intake levels of diabetics with those of the general population. In response to these questions, a food label survey was initiated to map the occurrence of sweeteners in foods and in table-top sweeteners on the Belgian market, while chemical analysis of a representative number of foods was considered essential to gain insight in the concentrations being used. Resulting concentration levels were used for subsequent intake estimations, which were based on a tiered approach in view of harmonization with intake studies of other Member States (European Commission 2004). Both Tier 2 and Tier 3 approaches were used to assess a realistic intake of selected sweeteners and to calculate contribution of table-top sweeteners to the total dietary intake.

\section{MATERIALS AND METHODS}

\section{Food label survey}

The label survey was approached from the point of view that food additive labeling is mandatory, hence artificially-sweetened products were readily selected from label screening of $>2000$ food items in 7 major supermarkets with good market share in Belgium. Screening of table-top sweeteners, a well-defined group of sweetener-based products, was most apparent, but the set of sweetened foods was considerably larger and exceedingly divers. Therefore, Directive 94/35/EC, which includes an overview of foods legally allowed to contain sweeteners (European Parliament and Council 1994), was used as starting point from which food labels were explored. Relevant foods were inserted in an in-house database and organized in groups according to available national food consumption data (Vandevijvere et al. 2009), thus generating following food groups: nonalcoholic beverages, beers and alcoholic beverages, desserts and similar products, sweets including breath-freshening micro-sweets, chewing gums, canned and bottled foods, marmalades, sauces, and cereals. Information from these products, including brand name, producer name, physical state, 
93

ingredients, sweetener content, labeled warnings, supermarket name, day of visit, and batch number were registered in the database. Duplicates, i.e. identical products found at different locations or supplied in varying packaging (a particular drink, for example, supplied in cans, PET-bottles or glass bottles) were counted only once. Screening was performed from December 2009 till February 2010.

\section{Chemicals}

Acesulfame-K and sodium saccharinate were obtained from Fluka (Buchs, Switzerland), while sodium cyclamate, sucralose, and sulfadimidine came from Sigma (St. Louis, MO, USA). Aspartame was purchased from Supelco (Bellefonte, PA, USA), while ammonium acetate was a product from Acros (Geel, Belgium). All chemicals were of analytical grade. Methanol (HPLC-grade) was obtained from Biosolve (Valkenswaard, The Netherlands), while purified, de-ionized water $(\mathrm{R}=18 \mathrm{M} \Omega \mathrm{cm}$, total organic content $<4 \mathrm{ppb})$ was produced by a MilliQ unit (Millipore, Billerica, MA, USA).

\section{Analytical methodology}

\section{Sample Preparation}

The complexity and heterogeneity of certain foods such as confectionery, biscuits, and dairy products required thorough sample preparation, which, for the sake of throughput, was preferentially universally applicable. Initially, solid phase extraction (SPE), which is classic in analyses of complex samples, was applied for foods, but low affinity of saccharin and acesulfame salts for the $\mathrm{C}_{18}$-packing material resulted in poor reproducibility. In this respect, it was recently reported that retention of these compounds on SPE cartridges is highly dependent on the type and manufacturer of the packing material (Zygler et al. 2010). Alternative sample preparations were thus investigated and reported methods for beverages or a specific food group (Koyama et al. 2005; Wasik et al. 2007; Yang et al. 2009) were further optimized for use with the proposed set of complex and diverse matrices. It is worth noting that sweeteners in foods and particularly in table-top sweeteners were relatively highly 
121 concentrated, hence samples needed dilution prior to analysis. Thus, following preparation

122

123

124

125

126

127

128

129

130

131

132

133

134

135

136

137

138

139

140

141

142

143

144

145

146

147

148

procedures for different matrices based on homogenization and dilution were elaborated.

Table-top sweeteners. Pellets or cubes were initially milled in a coffee grinder, while, obviously, formulations in aqueous solution required no additional homogenization. Approximately $50 \mathrm{mg}$, or $0.5 \mathrm{~mL}$ for liquid formulations, of the homogenized sample was taken, followed by addition of $500 \mu \mathrm{L}$ of a 1000-ppm sulfadimidine (internal standard, IS) solution in methanol. The resulting mixture was diluted to $25 \mathrm{~mL}$ with water/methanol (1:1, $\mathrm{v} / \mathrm{v}$ ) and subsequently sonicated for $10 \mathrm{~min}$. Then, $1 \mathrm{~mL}$ of the solution was centrifuged for 5 min at $4{ }^{\circ} \mathrm{C}$ and at $5000 \mathrm{rpm}$ (Avanti J25 centrifuge with $\mathrm{J}-10$ rotor, Beckman, Brea, CA, USA). The supernatant was isolated, $100 \mu \mathrm{L}$ was taken and diluted with water $(1: 400, \mathrm{v} / \mathrm{v})$. After subsequent filtering $(0.45 \mu \mathrm{m})$, the sample was ready for injection.

Foods and beverages. Similar as for table-top sweeteners, solid foods were initially milled in a grinder. Then, to approximately $0.5 \mathrm{~g}$ of the respective sample (or to $1 \mathrm{~mL}$ for beverages), $250 \mu \mathrm{L}$ of a $100-p p m$ sulfadimidine solution in methanol was added. The resulting mixture was diluted to $25 \mathrm{~mL}$ with water/methanol $(1: 1, \mathrm{v} / \mathrm{v})$ and exposed to ultrasones for $10 \mathrm{~min}$. The sample was then left for cold precipitation (ice bath, $2 \mathrm{~h}$ ), after which $1 \mathrm{~mL}$ of the resulting supernatant was centrifuged for $10 \mathrm{~min}$ at $13,000 \mathrm{rpm}$ (Biofuge Pico, Heraeus, Buckinghamshire, UK). Finally, $200 \mu \mathrm{L}$ of the thus isolated supernatant was diluted with water $(1: 20, v / v)$ and after filtration, the mixture was ready for injection.

\section{Chromatography}

Samples for chromatography were placed immediately after preparation in a thermostatized sample rack (at $5^{\circ} \mathrm{C}$ ) of a Surveyor autosampler with built-in LC pump (Thermo Electron Corp., San Jose, CA, USA). Sample injection (20 $\mathrm{LL})$ occurred in full loop mode and was preceded by washing and flushing of the injection needle with methanol $(2 \times 400 \mu \mathrm{L})$. Sweeteners were separated using an analytical Waters Symmetry $C_{18}$-column $(150 \mathrm{~mm} \times 2.1$ $\mathrm{mm}, 5 \mu \mathrm{m}$ ) (Waters Corporation, Milford, MA, USA), equipped with corresponding guard column and installed in the column oven (set at $50^{\circ} \mathrm{C}$ ) of the Surveyor station. Gradient 
149 elution was optimized using a solvent system consisting of water (solvent $A$ ) and methanol

150 (solvent B), each with $20 \mathrm{mM}$ ammonium acetate added. Eventually, following gradient 151 profile with satisfying separation was applied: 0 to 2 min at $5 \% \mathrm{~B}$, raise to $49 \% \mathrm{~B}$ in $12 \mathrm{~min}$, 152 raise to $100 \% \mathrm{~B}$ in $1 \mathrm{~min}$, stay for $2 \mathrm{~min}$, return to $5 \% \mathrm{~B}$ in $1 \mathrm{~min}$ and stay for $10 \mathrm{~min}$. 153 Retention times of the sweeteners eluting under these conditions are shown in Table 1.

Detection

156 Sweetener elution was monitored by ion trap mass spectrometry with electrospray ionization 157 source (LCQ Deca XP mass spectrometer, Thermo Electron Corp.). Ionization parameters 158 were optimized for the selected sweeteners to obtain reproducible fragmentation of the 159 respective compounds. The settings for the electrospray source were capillary voltage $-34 \mathrm{~V}$ 160 and tube lens offset $-10 \mathrm{~V}$ for acesulfame-K, saccharin, and cyclamate and $-4 \mathrm{~V}$ and $20 \mathrm{~V}$ for 161 sucralose, aspartame, and the internal standard. Except for sucralose, ion isolation width 162 was $m / z 1$, activation $Q$ was 0.25 , and activation time was $30 \mathrm{~ms}(4,0.2$, and 35 , 163 respectively, for sucralose). For all compounds, absolute spray voltage was $5 \mathrm{kV}$ and 164 capillary temperature was $375^{\circ} \mathrm{C}$. Indeed, the high concentration of water with first-eluting compounds required high capillary temperature to overcome surface tension of sprayed micro-droplets. For the same reason, significant sheath and sweep nitrogen gas flows were 167 applied (set at 45 and 20 arbitrary units, respectively). Collision energy needed for fragmenting saccharin and cyclamate was too high to yield stable ions, hence only fictitious transitions for these compounds were monitored. Unlike other sweeteners, aspartame was detected in positive ionization mode. Under similar conditions, the molecular ion of

171 sulfadimidine, the internal standard $(\mathrm{m} / \mathrm{z} 279$ in positive mode) was fragmented to give ions $172 \quad m / z 186.1$ and $m / z 203.9$.

174 Calibration

175 Quantification of the different compounds was based on external calibration curves 176 constructed by injecting a series of standard concentrations. Since no matrix effect was 
177 observed for beverages, dairy products, and confectionary, calibration in solution was used.

178 Sodium saccharinate and sodium cyclamate were used for calibration and analytical results 179 for these compounds therefore refer to concentrations of the salts rather than the corresponding free acids. The calibration is controlled by internal standard (sulfadimidine at $50 \mathrm{ppb})$.

182

\section{Validation}

184

The performance of the sweetener quantification method was evaluated by determining selectivity, linear range, recovery, precision, detection and limit of quantification. Risk of interference was practically non-existent for compounds with unique transitions, but for cyclamate and saccharin, for which detection solely relied on retention time and molecular mass, the degree of selectivity might be lower. Nevertheless, blanks from beverages, yoghurt, and sweets lacked signals, while, after spiking these matrices, sweeteners were readily detected at their expected retention time which demonstrated acceptable selectivity.

After injection of blank samples to measure noise levels at relevant retention times, the limit of detection (LOD) was determined by injecting standard solutions to reach a signal-to-noise ratio $(\mathrm{S} / \mathrm{N})$ of 3 (Table 2). The limit of quantification (LOQ) was then determined as the concentration at which $\mathrm{S} / \mathrm{N}$ gives 10 . The linearity of detector response was obtained over a large concentration range for the five compounds (Ace-K: 20-4000 ng mL $\mathrm{mL}^{-1}$, Asp: $20-10000$ ng mL ${ }^{-1}$, Cyc: $20-4000 \mathrm{ng} \mathrm{mL}^{-1}$, Sacc: $20-4000 \mathrm{ng} \mathrm{mL}^{-1}$, Sucr: $20-4000 \mathrm{ng} \mathrm{mL}^{-1}$, which is useful due to the high variation in sweetener concentration in sampled foods and table-top sweeteners. Resulting calibration curves followed first order regression with correlation coefficients $\left(R^{2}\right)$ of 0.998 for acesulfame-K, 0.994 for saccharin, 0.994 for cyclamate, 0.995 for sucralose, and 0.992 for aspartame.

Method precision and accuracy were assessed for a complex matrix (sweets), which did not contain any of the analytes under investigation. To a homogenized matrix was added a mix 
205 of the respective sweeteners to reach three different final concentrations, namely $0.5 \mathrm{~g} \mathrm{~kg}^{-1}$ 206 (low), $1 \mathrm{~g} \mathrm{~kg}^{-1}$ (medium), and $1.5 \mathrm{~g} \mathrm{~kg}^{-1}$ (high), an experiment that was performed in triplicate 207 and repeated on three non-consecutive days. The resulting $27(3 \times 3 \times 3)$ samples were 208 analyzed according to the reported procedure and validation results were described in Table 2. Herein, recovery was determined by the ratio of the average medium concentration and its corresponding theoretical value $\left(1 \mathrm{~g} \mathrm{~kg}^{-1}\right)$.

\section{Intake assessment}

A uniform methodology, designed by members of the SCOOP task force in view of realizing harmonized additive intake assessments, was previously reported and consisted of a 3phase approach (European Commission 2004). Tier 1, which is based on theoretical food 94/35/EC (European Parliament and Council 1994), is a conservative intake estimate carried out at European level and is not a task for Member States. Tier 2 and Tier 3 refer to assessment at the level of individual Member States and are based on a combination of national food consumption data with maximum permitted levels (Tier 2) and with actual use levels (Tier 3), respectively.

Consumption data from the Belgian Food Consumption Survey (dating from 2004) were used to perform the intake assessment. Aims, design and methods of this survey can be found elsewhere (Vandevijvere et al. 2009). The target population comprised all Belgian inhabitants of 15 years or older. The sample included 3245 participants randomly selected from the National Register using a multi-stage stratified procedure. Information on dietary intake was collected by two non-consecutive $24-\mathrm{h}$ recalls in which the respondent reported the quantity of all foods and beverages consumed during the preceding day. Both 24-h recalls, which were carried out using EPIC-SOFT software (Slimani et al. 2002), were completed by 3083 participants (hence 6166 recalls including 428 from diabetics). 


$$
\mathrm{y}_{\mathrm{i}}=\frac{\mathrm{c}_{\mathrm{i}} \times \mathrm{x}_{\mathrm{i}}}{\mathrm{bw} \mathrm{w}_{\mathrm{i}}}
$$

234

The individual intake of each sweetener from a certain food product was calculated by Equation 1. Herein, $y_{i}$ is the intake of the particular sweetener by individual i from a particular food on an interview day $\left(\mathrm{mg} \mathrm{kg}^{-1}\right.$ bodyweight day $\left.{ }^{-1}\right) ; \mathrm{c}_{\mathrm{i}}$ is the concentration of the sweetener in the food $\left(\mathrm{mg} \mathrm{kg}^{-1}\right) ; \mathrm{x}_{\mathrm{i}}$ is the consumption of a certain food by individual $\mathrm{i}(\mathrm{kg})$; and bw $\mathrm{w}_{\mathrm{i}}$ is the self-reported bodyweight of individual $\mathrm{i}(\mathrm{kg})$. To estimate the total intake of each sweetener per food group per day, individual daily intakes of the sweeteners from different foods were added up. In the Tier 2 approach, $c_{i}$ represents the maximum permitted concentration in each food, while in the Tier 3 approach, $c_{i}$ represents the actual mean concentration of the sweetener observed in a particular food. Minor food groups that were not sampled were assigned maximum concentrations in Tier 3 (as in Tier 2), while others were excluded due to the lack of consumption of some foods listed in Directive $94 / 35 / \mathrm{EC}$ or to the fact that no sweeteners were found on the labels of food belonging to these products (such as sauces, bakery products for special nutrition, foods intended to be consumed in energy-restricted diets, dietetic foods for special medical purposes, liquid nutritional supplements and solid food supplements, spirits with an alcohol content of less than $15 \%$, tablets with reduced sugar, essoblaten, and Feinkost salat). The usual intake distribution for sweeteners was estimated with the Nusser-method (Nusser et al. 1996) using the C-side software (lowa State University 1996). Several statistical methods are available to estimate usual intake distributions with the correct mean, variance and skewness. These statistical procedures adjust for within-person or day-to-day variability. The usual intake distribution was weighted for the age and sex distribution of the Belgian population and adjusted for day of the week and season. Usual intake was reported absolutely (as $\mathrm{mg} \mathrm{kg}^{-1}$ bodyweight day ${ }^{-1}$ ) or relatively against the ADI of the respective sweeteners.

258

\section{RESULTS \& DISCUSSION}


260

261

262

263

264

265

266

267

268

269

270

271

272

273

274

275

276

277

278

279

280

281

282

283

284

285

286

287

\section{Label survey}

For the presentation of the results of the label survey, it was decided to treat table-top sweeteners and foods separately due to differences in both legislation and practical use of the two groups. Indeed, according to regulation 1333/2008, table-top sweeteners are defined as preparations of permitted sweeteners, which may contain other food additives and/or food ingredients and which are intended for sale to the final consumer as a substitute for sugars (European Parliament and Council 2008). The latter implies that, unlike in foods, concentrations of sweeteners in table-top sweeteners are not determined by legislation and usage is according to consumer preference. Aspartame was most frequently found (Figures $1 \mathrm{~A}$ and $\mathrm{C}$ ) and was used as single sweetener or in combination with primarily acesulfame- $\mathrm{K}$ (Figure 1B). Saccharin and cyclamate were another popular combination and, due to their stability and pronounced solubility, they were exclusively used in aqueous sweetener solutions. Products based on neohesperidine dihydrochalcone, thaumatin, or neotame were not found.

Unlike table-top sweeteners, which basically contained bulk materials with high concentrations of sweeteners, ingredient lists of the heterogeneous set of sweetened foods were considerably more complicated. A total of 270 labels, divided over 10 different food groups according to consumption data, were examined. The most important group was the set of beverages, including beer and non-alcoholic drinks, which, together, represented more than half of the total supply of sweetened foods (Figure 2A). Acesulfame- $K$ and aspartame were used most frequently (Figure 2B), while also a relatively large number of beverages was sweetened with sucralose compared to the 5 items found during a similar study in 2004 (Belgian Scientific Institute of Public Health 2005). This sweetener was also found in a significant number of other foods (67 in total), which nicely complied with recent findings on high sucralose presence (up to $365 \mathrm{ng} \mathrm{L}^{-1}$ ) in Belgian river waters (Loos et al. 2009). Similar as observed for table-top sweeteners, results showed that compounds were often combined in an attempt to mask or eliminate unwanted aftertastes (Figure 2C). Only 1 food item 
(beverage) was found to contain neohesperidin dihydrochalcone, hence the decision to leave this and other recently approved sweeteners out of the study was justified.

\section{Analysis method}

Despite the fact that various methods have been described, development and optimization of an analytical methodology was pursued to meet the specific objectives set for this work. A method based on simple dilution followed by filtration, which was previously found effective for drinks and table-top sweeteners (Zygler et al. 2009), was optimized for more complicated matrices by introduction of a cooling phase followed by ultracentrifugation of the resulting supernatant. As for the chromatography, use of triethylamine in the mobile phase (as in methods by Huang et al. 2006; Wasik et al. 2007; Yang et al. 2009) was avoided due to persistent memory effects with mass spectrometric detection (Rutters et al. 2000). Instead, ammonium acetate was preferred as additive (Scheurer et al. 2009). Details of chromatography and mass spectrometric detection of sweeteners are given in Table

\section{Concentrations of sweeteners in table-top sweeteners and foods}

Samples of table-top sweeteners were prepared and analyzed according to the procedure described in the experimental section. All table-top sweeteners found during the food label survey $(n=30)$ were sampled and qualitative analysis results complied with data extracted from the label. Liquid table-top sweeteners were exclusively composed of cyclamate and saccharin and doses amounting to $\sim 80 \mathrm{~g} \mathrm{~L}^{-1}$ for the sum of the two sweeteners were measured. Next to cyclamate and saccharin, solid table-top sweeteners contained high levels of aspartame so that a total sweetener content of up to $40 \%$ of the total mass was reached. In this respect, pellets were significantly more concentrated than powders, which are normally consumed in larger portions. Average concentrations of sweeteners in positive samples (Table 3) confirmed the notion that cyclamate, having the weakest sweetening power, is used in the highest concentrations. 
316 For analyses of foods, 89 samples, which were a representative distribution of sweetened

317 products found on the market, were selected for analysis (Table 3 ). In one case, aspartame 318 was labeled but was not detected as such, probably due to degradation during storage 319 (despite that analysis was carried out prior to expiry date) (Hutchinson et al. 1999). Only one 320 sample (beer) was found in which the listed sweetener (acesulfame-K) differed from the one 321 detected (saccharin), a result of inconsistent labeling as confirmed by the involved brewery. 322 Reconstituting sweetener composition of sampled beer and beverages based on analytical 323 data, showed that sweeteners in beer were relatively low concentrated compared to non324 alcoholic drinks. Beers mostly contained saccharin or acesulfame-K, which were favored 325 over cyclamate (not allowed in beer) and aspartame (unstable in acidic media). Acesulfame$326 \mathrm{~K}$ was also abundantly used in nonalcoholic drinks, despite its unpleasant bitter aftertaste 327 (Kuhn et al. 2004). For this reason, it often appears in combination with aspartame and 328 cyclamate, the latter, due to its low sweetening power, is higher concentrated. The former 329 combination (i.e., aspartame and acesulfame-K) dominates other food groups as well and 330 particularly chewing gum was characterized by high quantities of these compounds. Indeed, 331 Directive 94/35/EC (European Parliament and Council 1994) permits acesulfame-K levels up 332 to $2000 \mathrm{mg} \mathrm{kg}^{-1}$ while aspartame can be concentrated as high as $5500 \mathrm{mg} \mathrm{kg}^{-1}$. In this 333 respect, one sample was found to contain a significant excess of acesulfame-K, while in 334 canned fruit ( 3 of 4 samples) acesulfame-K levels slightly exceeding the maximum permitted 335 level were found. Permitted concentrations of these and other sweeteners, as stated in the 336 sweetener directive, were not exceeded in other foods.

\section{Intake of artificial sweeteners in Belgium}

339 From the food label survey, it became clear that recently approved sweeteners 340 neohesperidine dihydrochalcone, thaumatin, and neotame were not found on the local 341 market, hence only intake of aspartame, cyclamate, acesulfame- $\mathrm{K}$, saccharin, and sucralose 342 was relevant. The Tier 2 was based on maximum permitted levels but despite the 343 conservative nature of this approach, usual intake of sweeteners for the $95^{\text {th }}$ percentile was 
significantly below established ADI values (Table 4). For diabetics, which were suspected of consuming higher amounts of sweeteners, observed intake (based on mean intake of 2 interview days) rather than usual intake was calculated because of the smaller subpopulation $(n=428)$. Thus, for p95 the observed intake was found to be $3.75 \pm 1.30,6.53 \pm 2.32,2.06 \pm$ $0.80,0.97 \pm 0.39$, and $3.03 \pm 1.07 \mathrm{mg} \mathrm{kg}^{-1}$ bodyweight day ${ }^{-1}$ for acesulfame- $\mathrm{K}$, aspartame, cyclamate, saccharin, and sucralose, respectively, which was not considerably different from observed intake of the entire population $(3.55 \pm 1.41,6.77 \pm 2.61,1.97 \pm 0.86,1.14 \pm 0.43$, and $3.08 \pm 1.20 \mathrm{mg} \mathrm{kg}^{-1}$ bodyweight day ${ }^{-1}$, respectively). Intake of table-top sweeteners was however not included in these figures because the lack of maximum permitted levels and their contribution could only be taken into account in Tier 3. This approach uses actual, mean concentrations (Table 3) (or maximum permitted levels for minor foods) for combination with food consumption data and is expected to be more accurate. Indeed, resulting lower intakes (Table 5) emphasize the conservative character of Tier 2. Contributions of table-top sweeteners were low and of minor significance: $0.06 \%, 0.05 \%, 0.44 \%$, and $0.17 \%$ of the respective $\mathrm{ADI}$ for acesulfame-K, aspartame, cyclamate, and saccharin, respectively. No intake data was obtained for sucralose due to its practical absence in table-top sweeteners. Similar as in the Tier 2, observed intake was calculated for diabetics and compared with the entire population. At p95, $1.48 \pm 0.60,1.36 \pm 0.72,1.20 \pm 0.47,0.57 \pm 0.23$, and $1.13 \pm 0.46$ $\mathrm{mg} \mathrm{kg}{ }^{-1}$ bodyweight day-1 were consumed of acesulfame- $\mathrm{K}$, aspartame, cyclamate, saccharin, and sucralose, respectively, by diabetics versus $1.96 \pm 0.78,2.46 \pm 1.01,1.18 \pm$ $0.52,0.60 \pm 0.23$, and $1.53 \pm 0.59 \mathrm{mg} \mathrm{kg}^{-1}$ bodyweight day ${ }^{-1}$ by the total population. Intake through consumption of table-top sweeteners was slightly higher for diabetics $(0.004 \pm 0.002$, $0.019 \pm 0.008,0.027 \pm 0.011$, and $0.008 \pm 0.003 \mathrm{mg} \mathrm{kg}^{-1}$ bodyweight day ${ }^{-1}$ of acesulfame- $\mathrm{K}$, aspartame, cyclamate, and saccharin, respectively) compared to the entire population $(0.002$ $\pm 0.001,0.008 \pm 0.005,0.011 \pm 0.008$, and $0.003 \pm 0.002 \mathrm{mg} \mathrm{kg}^{-1}$ bodyweight day ${ }^{-1}$, respectively), but was negligible with respect to established ADIs. Since usual intake remained significantly lower than reported ADIs, it was safely assumed that the adult Belgian population was not exposed to excessive intakes. 
Sweetener intake in other Member States

374

Belgian results were compared with contemporary intake assessments from other countries, including Italy (Arcella et al. 2004; Leclercq et al. 1999), the UK (UK Food Standards Agency 2003; Wilson et al. 1999), France (Bemrah et al. 2008; Garnier-Sagne et al. 2001), Spain (Serra-Majem et al. 2003), the Netherlands (van Rooij-van den Bos et al. 2004), and Denmark (Leth et al. 2008). These studies showed intakes significantly below the established ADI for the respective sweeteners (Table 6). Worst-case scenarios were evaluated as well (Hendriksen et al. 2011; Husoy et al. 2008; llback et al. 2003), but no significant exceeding of ADI was reported. As for table-top sweeteners, only few data on consumption were found. Arcella et al. (2004) reported a worst case scenario from Italy, in which only sugar-free alternatives were used at the highest observed concentration, but, despite the highly conservative assessment, p95 level of intake was far below the respective ADls $(12 \%, 29 \%$, $24 \%$, and $38 \%$ of $A D I$ for aspartame, acesulfame-K, saccharin, and cyclamate, respectively). In the same study, a realistic assessment based on a questionnaire gave slightly higher intake than for the Belgian population because the survey group was a selection of 389 consumers with high reported table-top sweetener intake (Table 6).

Although adults were not at risk of exceeding ADIs for the respective sweeteners, intake by children was possibly problematic according to a British study (UK Food Standards Agency 2003). Similar risks for cyclamate were purported in worst case scenarios from The Netherlands (van Rooij-van den Bos et al. 2004) and from Sweden (llback et al. 2003), but, on the other hand, intake assessments in Denmark (Leth et al. 2008), France (Bemrah et al. 2008), and Portugal (Lino et al. 2008) demonstrated that cyclamate intake in small children and young teenagers remained well below the ADI. Unfortunately, few data was available for this subgroup and the latter was certainly true for the Belgian Food Consumption Survey, which did not include individuals younger than 15 years. 
Few intake data were found from countries outside of EU, but comparison with European

401

402

403

404

405

406

407

408

409

410

411

412

413

414

415

416

417

418

419

420

421

422

423

424

425

426 results is difficult because of differences in both legislation and advised ADI levels. The latter, which are set by the WHO/FAO Joint Expert Committee on Food Addditives, differ for acesulfame-K $\left(15 \mathrm{mg} \mathrm{kg}^{-1}\right.$ day $^{-1}$ instead of $9 \mathrm{mg} \mathrm{kg}^{-1}$ day $\left.^{-1}\right)$ and for cyclamate $\left(11 \mathrm{mg} \mathrm{kg}^{-1}\right.$ day

${ }^{1}$ instead of $7 \mathrm{mg} \mathrm{kg}^{-1}$ day $\left.^{-1}\right)$. Still, intake studies from Australia and New-Zealand and from Korea showed that sweetener intake was below the respective ADIs (Chung et al. 2005; Food Standards Australia New-Zealand 2004).

\section{Conclusions}

A thorough food label survey, initiated to screen the presence of sweeteners in foods, showed that acesulfame-K, saccharin, cyclamate, aspartame, and sucralose were well distributed in the Belgian market. Intake assessment of these additives by the Belgian population older than 15 years was carried out and eventually demonstrated that the risk of the adult Belgian population (including possibly high consumers such as diabetics) for being excessively exposed to acesulfame- $\mathrm{K}$, saccharin, cyclamate, aspartame, and sucralose was of no concern. The intake of other permitted intense sweeteners such as neohesperidin dihydrochalcone (E959), neotame (E961), and thaumatin (E957), as well as the expected steviol glycosides, was currently not relevant, but expected future developments in sweetener formulation obviously justify future monitoring. Contrary to the safe consumption by adults, the possibility of exceeding ADI by children at the higher percentiles has been suggested in the literature. Accordingly, the Scientific Committee on Food urged to focus on additive intake by children, which, on a body weight basis, are at higher risk than adults for being exposed to excessive levels. However, as ADI is based on life-long exposure, a possible exceeding of the ADI in childhood is very likely compensated by a very low intake in adulthood (as shown by this work) and will thus not compromise the conclusions on the safety of the intake of sweeteners in Belgium. 


\section{Acknowledgments}

428 This work was funded by the Directorate-General Animal, Plant, and Food (DG 4) of the 429 Federal Service of Public Health, Safety of the Food Chain, and Environment. 


\section{References}

432 Arcella D, Le Donne C, Piccinelli R, Leclercq C. 2004. Dietary estimated intake of intense 433 sweeteners by Italian teenagers. Present levels and projections derived from the INRAN-RM434 2001 food survey. Food and Chemical Toxicology 42:677-685.

Belgian Scientific Institute of Public Health. 2005. Estimation de la dose journalière 436 d'édulcorants artificiels consommée par la population belge par l'intermédiaire de la consommation des boissons rafraîchissantes - Estimation à partir des quantités réelles d'édulcorants mesurées dans les boissons rafraîchissantes du marché belge (Projet additif 439 2004):1-123.

440 Bemrah N, Leblanc JC, Volatier JL. 2008. Assessment of dietary exposure in the french 441 population to 13 selected food colours, preservatives, antioxidants, stabilizers, emulsifiers 442 and sweeteners. Food Additives and Contaminants: Part B Surveillance 1:2-14.

443 Bray GA, Nielsen SJ, Popkin BM. 2004. Consumption of high-fructose corn syrup in 444 beverages may play a role in the epidemic of obesity. The American Journal of Clinical 445 Nutrition 79:537-543.

446 Chung MS, Suh HJ, Yoo W, Choi SH, Cho YJ, Cho YH, Kim CJ. 2005. Daily intake 447 assessment of saccharin, stevioside, D-sorbitol and aspartame from various processed foods 448 in Korea. Food Additives and Contaminants 22:1087-1097.

449 European Commission. 2004. Report from the Commission on Dietary Food Additive Intake 450 in the European Union. $\operatorname{COM}(2001) 542$ final:1-27.

451 European Parliament and Council. 1994. Directive 94/35/EC of 30 June 1994 on sweeteners 452 for use in foodstuffs. Official Journal of the European Union L237:3-12.

453 European Parliament and Council. 2008. Regulation (EC) No 1333/2008 of 16 December 4542008 on food additives. Official Journal of the European Union L354:16-33.

455 Ferrer I, Thurman EM. 2010. Analysis of sucralose and other sweeteners in water and 456 beverage samples by liquid chromatography/time-of-flight mass spectrometry. Journal of 457 Chromatography A 1217:4127-4134.

458 Food Standards Australia New-Zealand. 2004. Consumption of intense sweeteners in 459 Australia and New-Zealand: Benchmark Survey 2003. Evaluation Report Series N8. 
460 Garnier-Sagne I, Leblanc JC, Verger P. 2001. Calculation of the intake of three intense 461 sweeteners in young insulin-dependent diabetics. Food and Chemical Toxicology 39:745462749.

463 Gross LS, Li L, Ford ES, Liu S. 2004. Increased consumption of refined carbohydrates and 464 the epidemic of type 2 diabetes in the United States: an ecologic assessment. The American 465 Journal of Clinical Nutrition 79:774-779.

466 Hendriksen MA, Tijhuis MJ, Fransen HP, Verhagen H, Hoekstra J. 2011. Impact of 467 substituting added sugar in carbonated soft drinks by intense sweeteners in young adults in 468 the Netherlands: Example of a benefit-risk approach. European Journal of Nutrition 50:41-51.

469 Huang ZQ, Ma JY, Chen B, Zhang Y, Yao SZ. 2006. Determination of cyclamate in foods by 470 high performance liquid chromatography-electrospray ionization mass spectrometry. 471 Analytica Chimica Acta 555:233-237.

472 Husoy T, Mangschou B, Fotland TO, Kolset SO, Jakobsen HN, Tommerberg I, Bergsten C, 473 Alexander J, Andersen LF. 2008. Reducing added sugar intake in Norway by replacing sugar 474 sweetened beverages with beverages containing intense sweeteners - A risk benefit 475 assessment. Food and Chemical Toxicology 46:3099-3105.

476 Hutchinson SA, Ho GS, Ho CT. 1999. Stability and degradation of the high-intensity 477 sweeteners: Aspartame, alitame, and sucralose. Food Reviews International 15:249-261.

478 Ilback NG, Alzin M, Jahrl S, Enghardt-Barbieri H, Busk L. 2003. Estimated intake of the 479 artificial sweeteners acesulfame-K, aspartame, cyclamate and saccharin in a group of 480 Swedish diabetics. Food Additives and Contaminants 20:99-114.

481 lowa State University. 1996. A user's guide to C-SIDE. Software for Intake Distribution 482 Estimation. Department of Statistics and Center for Agricultural and Rural Development, 483 lowa State University, IA.

484 Koyama M, Yoshida K, Uchibori N, Wada I, Akiyama K, Sasaki T. 2005. Analysis of nine 485 kinds of sweeteners in foods by LC/MS. Journal of the Food Hygienic Society of Japan $486 \quad 46: 72-78$.

487 Kuhn C, Bufe B, Winnig M, Hofmann T, Frank O, Behrens M, Lewtschenko T, Slack JP, 488 Ward CD, Meyerhof W. 2004. Bitter taste receptors for saccharin and acesulfame K. Journal 489 of Neuroscience 24:10260-10265. 
Leclercq C, Berardi D, Sorbillo MR, Lambe J. 1999. Intake of saccharin, aspartame,

491

492

493

494

495

496

497

498

499

500

501

502

503

504

505

506

507

508

509

510

511

512

513

514

515

516

517

518

519

520 acesulfame $\mathrm{K}$ and cyclamate in Italian teenagers: present levels and projections. Food Additives and Contaminants 16:99-109.

Leth T, Jensen U, Fagt S, Andersen R. 2008. Estimated intake of intense sweeteners from non-alcoholic beverages in Denmark, 2005. Food Additives and Contaminants 25:662-668.

Lino CM, Costa IM, Pena A, Ferreira R, Cardoso SM. 2008. Estimated intake of the sweeteners, acesulfame- $K$ and aspartame, from soft drinks, soft drinks based on mineral waters and nectars for a group of Portuguese teenage students. Food Additives and Contaminants Part A-Chemistry Analysis Control Exposure \& Risk Assessment 25:12911296.

Loos R, Gawlik BM, Boettcher K, Locoro G, Contini S, Bidoglio G. 2009. Sucralose screening in European surface waters using a solid-phase extraction-liquid chromatography-triple quadrupole mass spectrometry method. Journal of Chromatography A 1216:1126-1131.

Ludwig DS, Peterson KE, Gortmaker SL. 2001. Relation between consumption of sugarsweetened drinks and childhood obesity: a prospective, observational analysis. The Lancet 357:505-508.

Mattes RD, Popkin BM. 2009. Nonnutritive sweetener consumption in humans: effects on appetite and food intake and their putative mechanisms. American Journal of Clinical Nutrition 89:1-14.

Nusser SM, Carriquiry AL, Dodd KW, Fuller WA. 1996. A semiparametric transformation approach to estimating usual daily intake distributions. Journal of the American Statistical Association 91:1440-1449.

Renwick AG. 2006. The intake of intense sweeteners - an update review. Food Additives and Contaminants A 23:327-338.

Rutters H, Mohring T, Rullkotter J, Griep-Raming J, Metzger JO. 2000. The persistent memory effect of triethylamine in the analysis of phospholipids by liquid chromatography/mass spectrometry. Rapid Communications in Mass Spectrometry 14:122123.

Scheurer M, Brauch HJ, Lange FT. 2009. Analysis and occurrence of seven artificial sweeteners in German waste water and surface water and in soil aquifer treatment (SAT). Analytical and Bioanalytical Chemistry 394:1585-1594. 
521 Serra-Majem L, Bassas L, Garcia-Glosas R, Ribas L, Ingles C, Casals I, Saavedra P, 522 Renwick AG. 2003. Cyclamate intake and cyclohexylamine excretion are not related to male 523 fertility in humans. Food Additives and Contaminants 20:1097-1104.

524

525 Shils ME, Shike M, Ross AC, Caballero B, Cousins RJ. 2005. Modern nutrition in health and 526 disease. 10th ed. Philadelphia, PA: Lippincott Williams \& Wilkins.Slimani N, Valsta L. 2002. 527 Perspectives of using the EPIC-SOFT programme in the context of pan-European nutritional 528 monitoring surveys: Methodological and practical implications. European Journal of Clinical 529 Nutrition 56: S63-S74.

530 Touger-Decker R, van Loveren C. 2003. Sugars and dental caries. The American Journal of 531 Clinical Nutrition 78:881S-892S.

532 UK Food Standards Agency. 2003. Diary survey of the intake of intense sweeteners by 533 young children from soft drinks. $36 / 03$

534 van Rooij-van den Bos, L, Konings, EJM, Heida, P, van Hamersveld, ICM, van der Wielen, J, 535 Kooijman, M. 2004. Onderzoek naar de kunstmatige zoetstoffen Sacharine, Aspartaam, 536 Acesulfaam-K en Cyclamaat in levensmiddelen. Gehaltebepaling en inname door de 537 Nederlandse populatie. SD 03 K120

538 Vandevijvere S, De Vriese S, Huybrechts I, Moreau M, Temme E, De Henauw S, De Backer 539 G, Kornitzer M, Leveque A, Van Oyen H. 2009. The gap between food-based dietary 540 guidelines and usual food consumption in Belgium, 2004. Public Health Nutrition 12:423-431.

541 Wasik A, McCourt J, Buchgraber M. 2007. Simultaneous determination of nine intense 542 sweeteners in foodstuffs by high performance liquid chromatography and evaporative light 543 scattering detection - Development and single-laboratory validation. Journal of 544 Chromatography A 1157:187-196.

545 Wilson LA, Wilkinson K, Crews HM, Davies AM, Dick CS, Dumsday VL. 1999. Urinary 546 monitoring of saccharin and acesulfame- $K$ as biomarkers of exposure to these additives. 547 Food Additives and Contaminants 16:227-238.

548 Yang DJ, Chen B. 2009. Simultaneous Determination of Nonnutritive Sweeteners in Foods 549 by HPLC/ESI-MS. Journal of Agricultural and Food Chemistry 57:3022-3027. 
550 Zygler A, Wasik A, Namiesnik J. 2009. Analytical methodologies for determination of artificial 551 sweeteners in foodstuffs. Trac-Trends in Analytical Chemistry 28:1082-1102.

552 Zygler A, Wasik A, Namiesnik J. 2010. Retention behaviour of some high-intensity 553 sweeteners on different SPE sorbents. Talanta 82:1742-1748.

554

555 
Figure 1. Total distribution of the various sweeteners (panel $A$, graph labels refer to absolute counting; relative counting \%), individual sweeteners or sweetener combinations applied in table-top sweeteners (panel B), and distribution per physical form (panel $C$ ) as determined from the label survey (Ace-K: Acesulfame-K; Asp: Aspartame; Cyc: Cyclamate; Sacc: Saccharin; Sucr: Sucralose).

Figure 2. Overview of foods with sweeteners added (panel $A$ ), total distribution of different sweeteners in these foods (panel $B$ ) (for both diagrams, graph labels refer to absolute counting; relative counting \%), and individual sweeteners or sweetener combinations applied in foods (pane/ $C$ ) as determined from the label survey (Ace-K: Acesulfame-K; Asp: Aspartame; Cyc: Cyclamate; N.I.: Not indicated, i.e. presence of sweeteners mentioned without further details; Neo: Neohesperidin dihydrochalcone; Sacc: Saccharin; Sucr: Sucralose). 


\section{Unable to Convert Image}

The dimensions of this image (in pixels) are too large to be converted. For this image to convert, the total number of pixels (height $x$ width) must be less than 40,000,000 (40 megapixels). 


\section{Unable to Convert Image \\ The dimensions of this image (in pixels) are too large to be converted. For this image to convert, the total number of pixels (height $x$ width) must be less than 40,000,000 (40 megapixels).}


1 Tables

4

5

2 Table 1. Details of chromatography and mass spectrometric detection of sweeteners 3

\begin{tabular}{ccccccc} 
Compound & $\mathbf{R T}^{a}(\mathrm{~min})$ & $\mathbf{M o d e}^{b}$ & $\mathbf{M I}^{c}(\mathrm{~m} / \mathrm{z})$ & $\mathbf{C E}^{d}(\%)$ & Fragments $(\mathrm{m} / \mathrm{z})^{\text {Loss of }}$ \\
\hline Acesulfame-K & 2.6 & - & 162.0 & 30 & 82.0 & sulfonate \\
Saccharin & 4.8 & - & 182.0 & 30 & 182.0 & - \\
Cyclamate & 8.1 & - & 178.1 & 30 & 178.1 & - \\
Sucralose & 11.1 & - & 395.2 & 24 & 359.0 & chlorine \\
& & & 397.1 & & 361.0 & chlorine \\
Aspartame & 12.6 & + & 295.1 & 30 & 277 & water \\
& & & & & 262.9 & methanol \\
& & & & & 235.0 & methyl ester
\end{tabular}

$5 \quad{ }^{a} \mathrm{RT}$ : Retention time. ${ }^{b}$ Ionization mode. ${ }^{c}$ Molecular ion. ${ }^{d} \mathrm{CE}$ : Normalized collision

6 energy (expressed relative to the maximum value of $80 \mathrm{eV}$ ). 
9 Table 2. Method performance parameters

\begin{tabular}{|c|c|c|c|c|c|c|c|}
\hline \multirow[b]{2}{*}{ Compound } & \multirow{2}{*}{$\begin{array}{l}\text { lod } \\
\left(\mu \mathrm{g} \mathrm{L}^{-1}\right)\end{array}$} & \multirow{2}{*}{$\underset{\left(\mu g^{-1}\right)}{\operatorname{loq}}$} & \multirow[b]{2}{*}{ Recovery (\%) } & \multicolumn{3}{|c|}{ RSD WD ${ }^{a}(\%)$} & \multirow[b]{2}{*}{$\left.\operatorname{RSD}^{B^{e}}{ }^{e} \%\right)$} \\
\hline & & & & $\mathbf{L}^{b}$ & $\mathbf{M}^{\mathrm{c}}$ & $\mathbf{H}^{d}$ & \\
\hline Acesulfame-K & 2.5 & 10 & 102 & 4 & 3 & 3 & 4 \\
\hline Saccharin & 5 & 20 & 99 & 5 & 1 & 3 & 4 \\
\hline Cyclamate & 5 & 20 & 97 & 11 & 1 & 3 & 5 \\
\hline Sucralose & 20 & 50 & 98 & 8 & 11 & 4 & 2 \\
\hline Aspartame & 5 & 10 & 98 & 4 & 5 & 2 & 12 \\
\hline
\end{tabular}

${ }^{a}$ RSD WD: Within day relative standard deviation. ${ }^{b} \mathrm{~L}$ : low concentration $\left(0.5 \mathrm{~g} \mathrm{~kg}^{-1}\right)$. ${ }^{c} \mathrm{M}$ : medium $\left(1 \mathrm{~g} \mathrm{~kg}^{-1}\right) .{ }^{d} \mathrm{H}$ : high $\left(1.5 \mathrm{~g} \mathrm{~kg}^{-1}\right) .{ }^{e} \mathrm{RSD} \mathrm{BD}$ : Between day relative standard deviation. 
1

2

16 Table 3. Mean sweetener concentrations of positive samples

\begin{tabular}{lcccccc} 
& \multicolumn{7}{c}{ Sweeteners } & & \\
Food group ( $n$ ) & Ace-K & Sacc & Cyc & Sucr & Asp & unit \\
\hline Table-top sweetener (30) & & & & & & \\
$\quad$ Cube (1) & 0.8 & - & - & - & 5 & $\mathrm{~g} \mathrm{~kg}^{-1}$ \\
Pellet (10) & 58 & 103 & 356 & - & 243 & $\mathrm{~g} \mathrm{~kg}^{-1}$ \\
Powder (14) & 5 & 4 & 66 & - & 22 & $\mathrm{~g} \mathrm{~kg}^{-1}$ \\
Liquid (5) & - & 6 & 58 & - & - & $\mathrm{g} \mathrm{L}^{-1}$ \\
Nonalc. drinks - total (46) & $\mathbf{8 9}$ & $\mathbf{3 1}$ & $\mathbf{1 5 3}$ & $\mathbf{5 3}$ & $\mathbf{4 8}$ & $\mathrm{mg} \mathrm{L}^{-1}$ \\
Energy (2) & 20 & - & 61 & 81 & 15 & $\mathrm{mg} \mathrm{L}^{-1}$ \\
Aromatized water (5) & 35 & - & - & 28 & 47 & $\mathrm{mg} \mathrm{L}^{-1}$ \\
Carbonated (19) & 88 & 27 & 173 & 54 & 45 & $\mathrm{mg} \mathrm{L}^{-1}$ \\
Based on fruit juice (14) & 107 & 33 & 152 & 30 & 59 & $\mathrm{mg} \mathrm{L}^{-1}$ \\
Based on milk (4) & 201 & 41 & 158 & 166 & 85 & $\mathrm{mg} \mathrm{L}^{-1}$ \\
Sports (2) & 55 & - & - & - & - & $\mathrm{mg} \mathrm{L}^{-1}$ \\
Beers - total (16) & $\mathbf{2 8}$ & $\mathbf{1 3}$ & - & - & $\mathbf{3 2}$ & $\mathrm{mg} \mathrm{L}^{-1}$ \\
Reduced alcohol (2) & 36 & - & - & - & - & $\mathrm{mg} \mathrm{L}^{-1}$ \\
Table beer (4) & 14 & 10 & - & - & - & $\mathrm{mg} \mathrm{L}^{-1}$ \\
Lambic beer (10) & 27 & 13 & - & - & 32 & $\mathrm{mg} \mathrm{L}^{-1}$ \\
Desserts (2) & - & - & - & $\mathbf{2 3 5}$ & - & $\mathrm{mg} \mathrm{kg}^{-1}$ \\
Chewing gum (6) & $\mathbf{1 7 4}$ & - & - & - & $\mathbf{2 1 5 1}$ & $\mathrm{mg} \mathrm{kg}^{-1}$ \\
Sweets (12) & $\mathbf{1 0 8 7}$ & - & - & $\mathbf{8 0 2}$ & $\mathbf{7 5 6}$ & $\mathrm{mg} \mathrm{kg}^{-1}$ \\
Marmalade (3) & - & $\mathbf{1 3 4}$ & $\mathbf{5 1 2}$ & - & - & $\mathrm{mg} \mathrm{kg}^{-1}$ \\
Canned fruit (4) & $\mathbf{5 0 1}$ & $\mathbf{1 6 8}$ & $\mathbf{6 2 3}$ & - & $\mathbf{2 9 4}$ & $\mathrm{mg} \mathrm{kg}^{-1}$
\end{tabular}

17

$18{ }^{a}$ Ace-K: Acesulfame-K; Sacc: Saccharin; Cyc: Cyclamate; Sucr: Sucralose; Asp: Aspartame. ${ }^{b}$ No positive samples detected. 
1

2

21 Table 4. Usual sweetener intake $\left(\mathrm{mg} \mathrm{kg}^{-1}\right.$ bodyweight day $\left.{ }^{-1}\right)$

22 by the adult Belgian population, as assessed by Tier 2 .

23

\begin{tabular}{|c|c|c|c|c|c|}
\hline \multirow{2}{*}{$\begin{array}{c}\text { Sweetener } \\
(A D I)\end{array}$} & \multirow{2}{*}{$\begin{array}{c}\text { Average } \\
\left(\mathrm{mg} \mathrm{kg}^{-1} \text { day }^{-1}\right)\end{array}$} & \multirow{2}{*}{$\begin{array}{c}\mathbf{S D}^{\mathrm{a}} \\
\left(\mathrm{mg} \mathrm{kg}^{-1} \text { day }^{-1}\right)\end{array}$} & \multirow[t]{2}{*}{ Percentile } & \multicolumn{2}{|c|}{ Intake $\left(\mathrm{mg} \mathrm{kg}^{-1}\right.$ day $\left.^{-1}\right)$} \\
\hline & & & & $\mathbf{A D}^{D}$ & $\% A D I$ \\
\hline \multirow{4}{*}{$\begin{array}{l}\text { Acesulfame-K } \\
\left(9 \mathrm{mg} \mathrm{kg}^{-1} \mathrm{day}^{-1}\right)\end{array}$} & 1.01 & 0.63 & p50 & 0.87 & 10 \\
\hline & & & p95 & 2.22 & 25 \\
\hline & & & p97.5 & 2.61 & 29 \\
\hline & & & p99 & 3.13 & 35 \\
\hline \multirow{4}{*}{$\begin{array}{c}\text { Aspartame } \\
\left(40 \mathrm{mg} \mathrm{kg}^{-1} \mathrm{day}^{-1}\right)\end{array}$} & 1.95 & 1.13 & p50 & 1.74 & 4 \\
\hline & & & p95 & 4.11 & 10 \\
\hline & & & p97.5 & 4.76 & 12 \\
\hline & & & p99 & 5.63 & 14 \\
\hline \multirow{4}{*}{$\begin{array}{c}\text { Cyclamate } \\
\left(7 \mathrm{mg} \mathrm{kg}^{-1} \text { day }^{-1}\right)\end{array}$} & 0.44 & 0.40 & p50 & 0.33 & 5 \\
\hline & & & p95 & 1.21 & 17 \\
\hline & & & p97.5 & 1.52 & 22 \\
\hline & & & p99 & 1.95 & 28 \\
\hline \multirow{4}{*}{$\begin{array}{c}\text { Saccharin } \\
\left(5 \mathrm{mg} \mathrm{kg}^{-1} \mathrm{day}^{-1}\right)\end{array}$} & 0.34 & 0.18 & p50 & 0.31 & 6 \\
\hline & & & p95 & 0.68 & 14 \\
\hline & & & p97.5 & 0.77 & 15 \\
\hline & & & p99 & 0.90 & 18 \\
\hline \multirow{4}{*}{$\begin{array}{c}\text { Sucralose } \\
\left(15 \mathrm{mg} \mathrm{kg}^{-1} \mathrm{day}^{-1}\right)\end{array}$} & 0.84 & 0.54 & p50 & 0.73 & 5 \\
\hline & & & p95 & 1.87 & 12 \\
\hline & & & p97.5 & 2.21 & 15 \\
\hline & & & p99 & 2.66 & 18 \\
\hline
\end{tabular}

24
25

25

26

27

28

29

30

31

32

33

34

35

36

37

38

39

40

41

42

43

44

45 
1

2
46 Table 5. Usual sweetener intake ( $\mathrm{mg} \mathrm{kg}^{-1}$ bodyweight day $\left.{ }^{-1}\right)$

47 by the adult Belgian population, as assessed by Tier 3 .

48

\begin{tabular}{|c|c|c|c|c|c|}
\hline \multirow{2}{*}{$\begin{array}{c}\text { Sweetener } \\
\text { (ADI) }\end{array}$} & \multirow{2}{*}{$\begin{array}{c}\text { Average } \\
\left(\mathrm{mg} \mathrm{kg}^{-1} \text { day }^{-1}\right)\end{array}$} & \multirow{2}{*}{$\begin{array}{c}\mathbf{S D}^{a} \\
\left(\mathrm{mg} \mathrm{kg}^{-1} \mathrm{day}^{-1}\right)\end{array}$} & \multirow[t]{2}{*}{ Percentile } & \multicolumn{2}{|c|}{ Intake $\left(\mathrm{mg} \mathrm{kg}^{-1} \mathrm{day}^{-1}\right)$} \\
\hline & & & & $\mathbf{A \mathbf { D } ^ { c }}$ & $\% A D I$ \\
\hline \multirow{4}{*}{$\begin{array}{l}\text { Acesulfame-K } \\
\left(9 \mathrm{mg} \mathrm{kg}^{-1} \mathrm{day}^{-1}\right)\end{array}$} & 0.53 & 0.35 & p50 & 0.46 & 5 \\
\hline & & & p95 & 1.21 & 13 \\
\hline & & & p97.5 & 1.42 & 16 \\
\hline & & & p99 & 1.71 & 19 \\
\hline \multirow{4}{*}{$\begin{array}{c}\text { Aspartame } \\
\left(40 \mathrm{mg} \mathrm{kg}^{-1} \text { day }^{-1}\right)\end{array}$} & 0.60 & 0.42 & p50 & 0.51 & 1 \\
\hline & & & p95 & 1.40 & 4 \\
\hline & & & p97.5 & 1.68 & 4 \\
\hline & & & p99 & 2.07 & 5 \\
\hline \multirow{4}{*}{$\begin{array}{c}\text { Cyclamate } \\
\left(7 \mathrm{mg} \mathrm{kg}^{-1} \text { day }^{-1}\right)\end{array}$} & 0.23 & 0.34 & p50 & 0.10 & 1 \\
\hline & & & p95 & 0.89 & 13 \\
\hline & & & p97.5 & 1.19 & 17 \\
\hline & & & p99 & 1.61 & 23 \\
\hline \multirow{4}{*}{$\begin{array}{l}\text { Saccharin } \\
\left(5 \mathrm{mg} \mathrm{kg}^{-1} \text { day }^{-1}\right)\end{array}$} & 0.15 & 0.11 & p50 & 0.12 & 2 \\
\hline & & & p95 & 0.37 & 7 \\
\hline & & & p97.5 & 0.43 & 9 \\
\hline & & & p99 & 0.52 & 10 \\
\hline \multirow{4}{*}{$\begin{array}{c}\text { Sucralose } \\
\left(15 \mathrm{mg} \mathrm{kg}^{-1} \text { day }^{-1}\right)\end{array}$} & 0.42 & 0.22 & p50 & 0.39 & 3 \\
\hline & & & p95 & 0.82 & 5 \\
\hline & & & p97.5 & 0.93 & 6 \\
\hline & & & p99 & 1.07 & 7 \\
\hline
\end{tabular}


Table 6. Overview of sweetener intake studies, based on a review by Renwick (Renwick 2006) but with inclusion of recent values reported in literature. Relative intakes are based on ADI levels as set by the Scientific Committee on Food (i.e., 9, $40,7,5$, and $15 \mathrm{mg} \mathrm{kg}^{-1}$ for acesulfame-K, aspartame, cyclamate, saccharin, and sucralose, respectively).

57

\begin{tabular}{|c|c|c|c|c|c|}
\hline \multirow{2}{*}{ Country } & \multirow{2}{*}{$\begin{array}{l}\text { Group } \\
\text { Teenager (13-19 y) } \\
\text { Teenager }(14-17 \mathrm{y})\end{array}$} & \multirow[b]{2}{*}{$\begin{array}{l}\text { Average intake } \\
0.1 \% \text { (Ace), } 0.1 \% \text { (Asp), } \\
3 \% \text { (Cyc), } 4 \% \text { (Sac) } \\
0.5 \% \text { (Ace), } 0.2 \% \text { (Asp), } \\
1 \% \text { (Cyc), } 0 \% \text { (Sac) }{ }^{a} \\
0.5 \% \text { (Ace), } 0.4 \% \text { (Asp), } \\
0.7 \% \text { (Cyc), } 0.6 \% \text { (Sac) }\end{array}$} & \multicolumn{2}{|c|}{ High consumer intake } & \multirow[b]{2}{*}{$\begin{array}{c}\text { Ref. } \\
\text { (Leclercq et } \\
\text { al. 1999) } \\
\text { (Arcella et } \\
\text { al. 2004) }\end{array}$} \\
\hline & & & p95 & $\begin{array}{l}\% \text { (Ace), 1\% (Asp), } \\
9 \% \text { (Cyc), 11\% (Sac) } \\
3 \% \text { (Ace), 0.7\% (Asp), } \\
8 \% \text { (Cyc), 0\% (Sac) }{ }^{a} \\
3 \% \text { (Ace), 2\% (Asp), } \\
4 \% \text { (Cyc), 5\% (Sac) }\end{array}$ & \\
\hline UK & Population (3-74 y) & $9 \%$ (Ace), $14 \%$ (Sac) & - & - & $\begin{array}{l}\text { (Wilson et } \\
\text { al. 1999) }\end{array}$ \\
\hline France & Adults ( $\geq 15 \mathrm{y}$ ) & $0.3 \%$ (Сус) & p97.5 & $2.9 \%$ (Сус) & $\begin{array}{l}\text { (Bemrah et } \\
\text { al. 2008) }\end{array}$ \\
\hline & Diabetics (2-20 y) & $\begin{array}{l}9 \% \text { (Ace), } 5 \% \text { (Asp), 6\% } \\
\text { (Sac) }\end{array}$ & p97.5 & $\begin{array}{l}27 \% \text { (Ace), } 20 \% \\
\text { (Asp), } 26 \% \text { (Sac) }\end{array}$ & $\begin{array}{l}\text { (Garnier- } \\
\text { Sagne et al. } \\
\text { 2001) }\end{array}$ \\
\hline Denmark & Population (1-80 y) & $\begin{array}{l}\text { 15\% (Ace), } 4 \% \text { (Asp), } \\
37 \% \text { (Cyc), } 8 \% \text { (Sac) }\end{array}$ & p99 & $\begin{array}{l}26 \% \text { (Ace), 5\% (Asp), } \\
51 \% \text { (Cyc), 1\% (Sac) }\end{array}$ & $\begin{array}{l}\text { (Leth et al. } \\
\text { 2008) }\end{array}$ \\
\hline Sweden & $\begin{array}{l}\text { Adult diabetics (16- } \\
90 \mathrm{y})\end{array}$ & $\begin{array}{l}<\text { ADI (Ace, Asp, Cyc, } \\
\text { and Sac) }\end{array}$ & p95 & $\begin{array}{l}45 \% \text { (Asp), } 114 \% \\
\text { (Cyc), } 46 \% \text { (Sac) }\end{array}$ & $\begin{array}{c}\text { (Ilback et al. } \\
\text { 2003) }\end{array}$ \\
\hline Norway & $\begin{array}{l}\text { Men (16-79 y) } \\
\text { Women (16-79 y) }\end{array}$ & $\begin{array}{l}2.5 \% \text { (Asp), } 3 \% \text { (Ace) } \\
3 \% \text { (Asp), 4\% (Ace) }\end{array}$ & $\begin{array}{l}p 95 \\
p 95\end{array}$ & $\begin{array}{l}11 \% \text { (Asp), } 12 \% \text { (Ace) } \\
14 \% \text { (Asp), 18\% (Ace) }\end{array}$ & $\begin{array}{c}\text { (Husoy et al. } \\
\text { 2008) }\end{array}$ \\
\hline Spain & Men $(30-50 y)$ & $6 \%$ (Сус) & - & - & $\begin{array}{l}\text { (Serra- } \\
\text { Majem et al. } \\
\text { 2003) }\end{array}$ \\
\hline $\begin{array}{l}\text { The } \\
\text { Netherlands }\end{array}$ & Population (1-97 y) & $\begin{array}{l}<0.5 \% \text { (Ace), <0.3\% } \\
\text { (Asp), } 1 \% \text { (Cyc), } 0.4 \% \\
\text { (Sac) }\end{array}$ & p95 & $\begin{array}{l}0.7 \% \text { (Ace), } 1 \% \text { (Asp), } \\
6 \% \text { (Cyc), } 0.4 \% \text { (Sac) }\end{array}$ & $\begin{array}{l}\text { (van Rooij- } \\
\text { van den Bos } \\
\text { et al. 2004) }\end{array}$ \\
\hline & $\begin{array}{l}\text { Men (19-30 y) } \\
\text { Women (19-30 y) }\end{array}$ & - & p95 & $\begin{array}{l}29 \% \text { (Ace), 6\% (Asp), } \\
37 \% \text { (Cyc), 4\% (Sac) } \\
27 \% \text { (Ace), 5\% (Asp), } \\
29 \% \text { (Cyc), 3\% (Sac) }\end{array}$ & $\begin{array}{l}\text { (Hendriksen } \\
\text { et al. 2011) }\end{array}$ \\
\hline
\end{tabular}

$58 \quad{ }^{a}$ Calculated based on consumption of soft drinks. ${ }^{b}$ Calculated based on consumption of table-top sweeteners by a group of females with high reported table-top sweetener intake. 